максимально эффективных решений и выполнения действий в соответствующих «областях ответственности».

Результаты оптимизации денежного потока компании отражены в системе планов формирования и использования средств в предстоящем периоде.

Формирование механизма оптимизации денежных потоков является одним из приоритетных направлений финансового управления предприятиями, однако для его эффективного осуществления глубокий качественный и количественный анализ. Использование современных методов экономического и математического моделирования является необходимым условием для регулирования и оптимизации денежных потоков предприятий. Именно такой подход позволит эффективно использовать средства и направлять их на развитие предприятия. [3, с. 181-185]

$$
* * *
$$

1. Быкова Е.В. / Показатели денежного потока в оценке финансовой устойчивости предприятия / Е.В. Быкова // Финансы. - 2010 - № 2.- С. 56-59

2. Климовских Н.В., Ашхотов В.Ю. Обеспечение устойчивого развития предпренимательских структур санаторно-курортного комплекса. Монография. / Н.В. Климовских, В.Ю. Ашхотов Нальчик: Издательство М. и Т. Котляровых, 2015

3. Красова О. Ю. Модель оптимизации денежных потоков в системе управления предприятием [Текст] / О. Ю. Красова, Н. П. Карлова // Проблемы иперспективы экономики иуправления: материалымеждунар. заоч. науч. конф. (г. Санкт-Петербург, апрель 2012 г.). — СПб.: Реноме, 2012. - C. $181-185$.

4. Овсийчук М.Ф. Управление денежными средствами предприятия / М. Ф. Овсийчук. // Аудитор. 2013. - №5. - С. 37 - 42.

\title{
Циркель Т.А., Кириллов Н.О. \\ Изучение сравнительного влияния на эффективность инвестиционно- производственных проектов некоторых показателей их внешней и внутренней среды
}

Российский экономический университет им. Г.В.Плеханова

(Россия, Кемерово)

doi:10.18411/spc-8-12-2017-17

idsp: 000001:spc-8-12-2017-17

Одной из важнейших сфер деятельности любого успешного предприятия являются операции вложения капитала в реализацию тех или иных инвестиционных проектов, которые, в свою очередь, будут обеспечивать компании получение выгод на протяжении длительного периода времени. Исходя из этого, в современном мире важной проблемой является определение наиболее эффективного направления вложения капитала с целью преумножения его стоимости, что объясняет актуальность выбранной темы исследовательской работы.

Потребность в реализации инвестиций может быть вызвана совокупностью различных факторов, однако, как правило, наиболее распространённым является инвестирование, нацеленное на стратегию роста бизнеса. Таким образом, инвестиции представляют собой непременное условие повышения уровня доходности и рентабельности реализуемой предпринимательской деятельности, что укрепляет позиции компании на рынке свободной конкуренции. Решить задачу выбора эффективной инвестиционной стратегии, без использования методов математического моделирования и автоматизированных программных комплексов финансового анализа, довольно трудно. В этой связи нами используется программный комплекс [3], предназначенный для получения оптимальных объемов инвестиций, производства и финансирования текущей деятельности предприятия на основе модели [1]. Серия предварительно проведенных расчетов позволила нам выдвинуть гипотезу о качественно различном влиянии на показатель внутренней нормы доходности (IRR) 
проекта различных характеристик проекта, определяемых его внутренней и внешней рыночной средой.

Для обоснования выдвинутой гипотезы проведем, с помощью [3], два вычислительных эксперимента по бизнес-проекту со следующими характеристиками (см. таблицу 1).

Таблица 1

\begin{tabular}{|c|c|c|}
\hline Наименование параметра проекта & Эксперимент №1 & Эксперимент №2 \\
\hline Количество видов продукции, шт & 1 & 1 \\
\hline Стоимость единицы ОПФ, д.е. & 80000 & 80000 \\
\hline Стоимость единицы продукции, д.е. & $30,40,52$ & 28 \\
\hline Срок службы ОПФ, лет & 20 & 20 \\
\hline Производительность ОПФ, ед.пр/едОПФ & 5100 & 5100 \\
\hline Спрос на продукцию, д.е. & 100000 & $100,300,500,1000$ \\
\hline Ставка НДС, доля & 0,18 & 0,18 \\
\hline Ставка НИ, доля & 0,02 & 0,02 \\
\hline Ставка НП, доля & 0,2 & 0,2 \\
\hline Ставка СВ, доля & 0,3 & 0,3 \\
\hline Трудоемкость, доля & 0,25 & 0,25 \\
\hline Материалоемкость, доля & 0,3 & 0,3 \\
\hline Срок кредита, лет & 5 & 5 \\
\hline Ставка кредита, доля & 0,3 & 0,3 \\
\hline Максимальная сумма начальных средств & 0 & 0 \\
\hline производителя, д.е. & 6000 & 6000 \\
\hline Максимальная сумма кредита, д.е. & 10000 & 10000 \\
\hline Максимальная сумма дотаций, д.е. & 1000 & 1000 \\
\hline Максимальная сумма инвестиций, д.е. & 6 & 6 \\
\hline Горизонт планирования, лет & 0,3 & 0,3 \\
\hline Ставка дисконтирования, доля & & \\
\hline
\end{tabular}

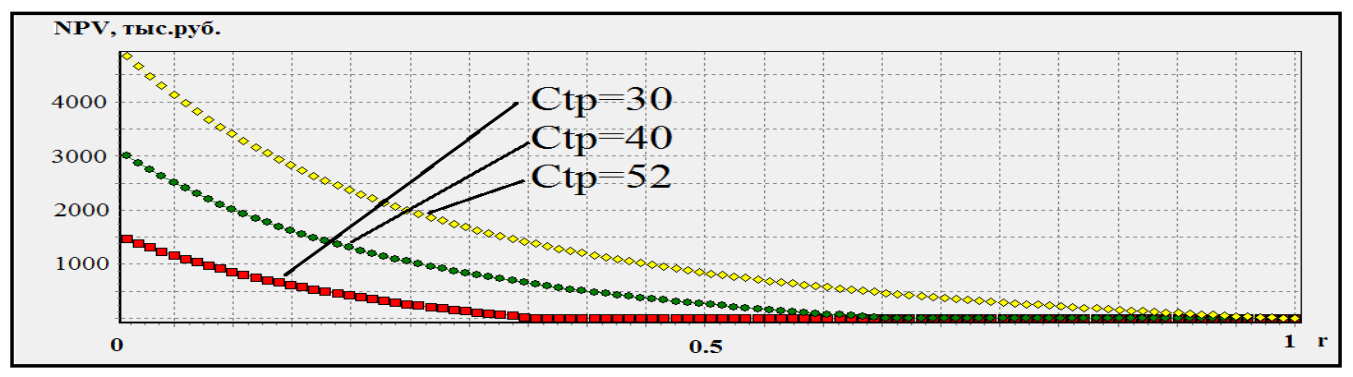

Рисунок 1 - зависимость NPV проекта от ставки дисконтирования r при варьировании стоимости единицы продукции Сtp

На рисунке 1 показана зависимость NPV проекта от ставки дисконтирования при варьировании стоимости единицы продукции Сtp. Отметим, что Ctp является внутрипроизводственной характеристикой проекта и существенно определяет его эффективность.

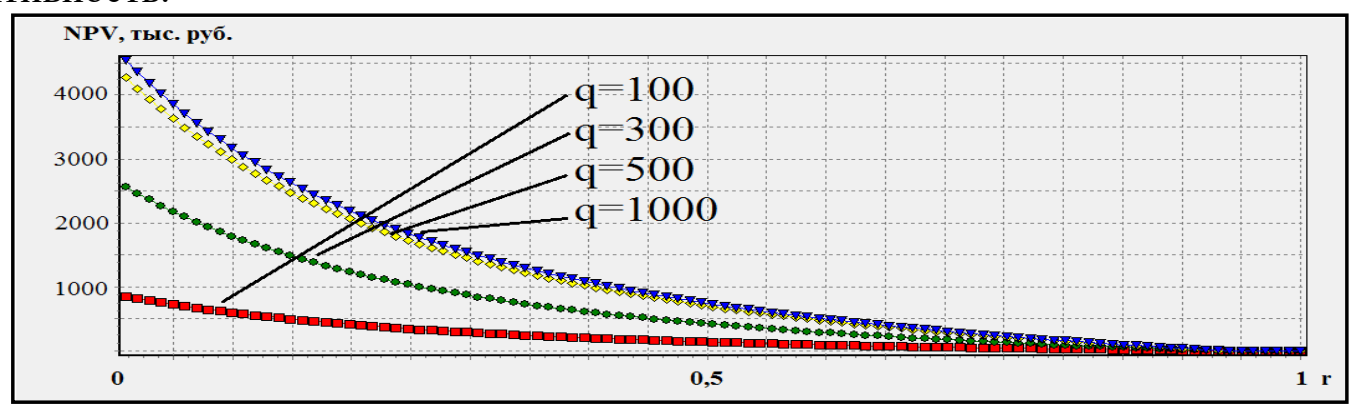

Рисунок 2 - зависимость NPV проекта от ставки дисконтирования r при варьировании спроса на продукцию q 
На рисунке 2 показана зависимость NPV проекта от ставки дисконтирования $r$ при варьировании спроса на продукцию q. Спрос на продукцию является внешней, рыночной характеристикой проекта и также существенно определяет его эффективность.

Сравнение рисунков 1 и 2 показывает их качественное отличие. При варьировании внутренней характеристики ИП точка пересечения графиков с осью абсцисс (внутренняя норма доходности, IRR) визуально смещается вправо с ростом $\mathrm{Ctp}$, а при варьировании спроса q графики не пересекаются с осью абсцисс, что свидетельствует о слабой зависимости IRR от данного показателя.

Таким образом, нами численно подтверждена выдвинутая выше гипотеза о том, что такая характеристика эффективности ИП, как IRR, в значительной мере определяется внутренними характеристиками проекта.

$$
* * *
$$

1. Медведев А.В. Оптимизационное планирование проектов функционирования экономических систем с заемным финансированием деятельности производителя // Фундаментальные исследования. - 2016. - №9(2). - С.273-278.

2. Медведев А.В. Инструменты оперативного принятия решений при оценке эффективности бизнеспроектов // Международный журнал прикладных и фундаментальных исследований. - 2016. - №9-2. - C.182-186.

3. Конструктор и решатель дискретных задач оптимального управления («Карма») Программа для ЭВМ. Свидетельство о регистрации в Роспатенте №2008614387 от 11.09.2008. Правообладатели: А.В. Медведев, П.Н. Победаш, А.В. Смольянинов, М.А. Горбунов.

\section{Чернопятов А.М., Макущенко Л.В. Становление и развитие предпринимательства в России}

Сургутский государственный педагогический университет (Россия, Сургут)

doi:10.18411/spc-8-12-2017-18

idsp: 000001:spc-8-12-2017-18

\section{Аннотация}

Исследованы теоретические и практические аспекты оценки и деятельности становления и развития предпринимательства и предпринимательской среды в Российской федерации.

Ключевые слова: Предпринимательство, экономика, реформы, инновации, новации, бизнес, конкуренция, ресурсы, хозяйствование.

Предпринимательство - это особый вид человеческого капитала, представленного деятельностью по координации и комбинированию всех других факторов производства в целях создания новых видов товаров и услуг (экономических благ). Главным в предпринимательстве - умение и желание внедрять в производство новые виды продукта, передовые технологии, современные формы организации бизнеса. При этом всегда присутствует риск[1]. В 80-х годов в Восточной Европе были начаты революционные экономические реформы, этим было вызвано нарастание экономических трудностей внутри СССР, а заодно и осмыслить новые реалии. Была поставлена стратегическая задача развития экономики в форме радикальной перестройки всей системы хозяйствования. Плановая экономика и директивная система стала разрушаться, образовывались точки для перехода к рыночной экономике. Соответственно, необходимым стало, принципиальное изменение отношения к конкуренции, частной собственности, предпринимательству[6].

С предпринимательством к 20-го века стали отождествлять прогресс, достижения материальной культуры. В 70-е годы, когда перед индустриальными 